\title{
EL CINE Y LA PINTURA: UNA RELACIÓN PEDAGÓGICA.
}

\author{
Una aproximación a Víctor Erice y Edward Hopper
}

\author{
Juan de Pablos Pons \\ Universidad de Sevilla
}

\begin{abstract}
Resumen
El artículo propone una aproximación analítica a las relaciones entre la pintura realista y el cine. La manera en la que estas manifestaciones artísticas han evolucionado compartiendo elementos comunes. El análisis de las relaciones entre pintura y cine aquí presentado, se centra en las figuras del director de cine español Víctor Erice y el pintor norteamericano Edward Hopper. El cineasta ha sido muy influido por la poética de algunos grandes pintores. El pintor norteamericano ha declarado su fascinación por el mundo del cine.
\end{abstract}

\section{Palabras clave}

Cine y pintura, educación artística, Víctor Erice, Edward Hopper.

\begin{abstract}
The article proposes an analytical approach to the relations between the realistic painting and the cinema. The way in which these artistic manifestations have evolved has common elements. The analysis of the relations between painting and cinema presented here, is centered in the figures of spanish cinema director Víctor Erice and north american painter Edward Hopper. The spanish
\end{abstract}


director has been influenced by important painter's poetry. The north american painter declared his fascination for the world of movies.

\section{Key words}

Cinema and painting, artistic education, Víctor Erice, Edward Hopper.

\section{La inmersión y la interactividad propiciadas por el cine y la pintura}

Las mutuas influencias entre la representación pictórica y la cinematográfica constituyen un campo analítico de gran interés. La vinculación entre la imagen pictórica y la tecnológica va más allá de los aspectos puramente formales en cuanto a la representación de la realidad. Cuando a finales del siglo XIX surgen la fotografía y el cine, todo un tipo de pintura parece quedar falto de sentido porque hay una invención técnica que representa la imagen de las apariencias con una gran fidelidad. El proceso de declive en el que parecen entrar las formas pictóricas realistas, fue avalado por las vanguardias de los primeros años del siglo XX y por la influencia de artistas con una poderosa personalidad como Picasso o Bacon.

La investigadora Marie-Laure Ryan (2004) plantea que diferentes tradiciones del arte occidental, en campos como la pintura y la literatura ya formularon muchas de las cuestiones que en los tiempos recientes han vuelto a suscitar las nuevas tecnologías digitales y su impacto en las manifestaciones artísticas. Siguiendo a esta autora cabe recordar que, con anterioridad al Renacimiento, la pintura era abordada como una representación simbólica de la espiritualidad, fundamentalmente religiosa y mitológica, frente a la idea de representación de la realidad propiamente dicha como documento histórico o pedagógico. Los artistas medievales representaban ideas y personajes de forma idealizada. El descubrimiento de las leyes de la perspectiva, de la que surge la representación de la profundidad, propicia un cambio fundamental en el concepto a representar, ya que sitúa al espectador ante el lienzo desde un punto de vista espacial. La perspectiva introduce virtualmente al espectador en el espacio del cuadro, permitiéndole hacerse presente en el mismo. Esta inmersión en unas coordenadas espaciales permiten a su vez llevar al observador de un cuadro al tiempo presente de la escena representada. Como señala Ryan esta inmersión virtual llega 
a su punto culminante con el Barroco, que difumina la distancia entre el espacio físico y el pictórico, al convertir al segundo en una continuación del primero (2004: 19).

Históricamente este estado de cosas en el campo de la pintura se constata con el hecho de la ausencia del retrato como género pictórico hasta fechas muy tardías. Las representaciones de reyes, dioses y grandes personajes en pinturas, esculturas o miniaturas reflejaban sus atributos y símbolos de poder o santidad y no sus rasgos físicos. En realidad, hablando del caso español, únicamente es a finales del siglo XV cuando el retrato, como manifestación claramente vinculada a la representación de lo real, empieza a tener relevancia.

El retrato barroco en España alcanza unos niveles altísimos de calidad con artistas únicos. Sin duda el más importante de ellos es el sevillano Diego Velázquez. Pintor de una técnica prodigiosa, su aportación artística representa una influencia imposible de obviar en la historia de la pintura universal. Su calidad y concepción pictóricas hacen que sus obras consigan el efecto de una representación de la sociedad de su tiempo, al permitir a los espectadores de sus cuadros la inmersión en la época y una “proximidad humana” a los personajes aristocráticos o plebeyos, que convivieron con el pintor. Su evolución hacia la madurez artística muestra un progresivo avance hacia la naturalidad, el análisis de la persona retratada, su psicología y circunstancias, lo que permite al espectador de sus cuadros captar una inmediatez y una proximidad extraordinarias.

En consecuencia, como creador fundamental para la evolución del concepto de representación de la realidad, cabe señalar su influencia decisiva para entender conceptos vinculados hoy a la posmodernidad como la inmersión y la interactividad. Esos ideales inmersivos generados por Velázquez y otros grandes pintores como Vermeer, Rembrandt, Ribera o Zurbarán han propiciado aproximaciones y distanciamientos valorativos a lo largo de la historia del arte. En consecuencia, “la ilusión óptica de un espacio penetrable” en palabras de Ryan ha sufrido a lo largo de la historia de la pintura, reconocimientos y adhesiones entusiastas, pero también rechazos e involuciones. Así, el impresionismo reelaboró el espacio tridimensional y la definición de las formas, solicitando al observador un proceso de interpretación y reconstrucción de los datos sensoriales. Las obras de Pissarro, Monet, Degas, Manet o Renoir plantean al espectador nuevas exigencias y compromisos interpretativos y una reelaboración cognitiva de las imágenes que se le proponen (Herbert, 1989).

En los primeros años del siglo XX el cubismo desestructura el espacio y la figuración, al forzar a quien observa las obras cubistas a situarse en diversos puntos de vista de manera simultánea. 
El cubismo y la abstracción llevan al espectador a un juego imaginativo, de manera que la evolución hacia el arte conceptual, nos aleja de los componentes que soportan la realidad representada.

El regreso a los referentes inmersivos se produce de manera periódica, de tal manera que en el segundo tercio del siglo XX el surrealismo recupera la imagen figurativa aunque con un espíritu provocador, siendo Salvador Dalí un ejemplo paradigmático de esta opción; en la actualidad el pintor manchego Antonio López reivindica el realismo como forma de entender lo que le ocurre al individuo a través de su representación o de su entorno, preferentemente urbano. En el campo literario, las representaciones que permiten la inmersión y la interactividad del lector, mediante técnicas que permiten una narración transparente, en la que “desaparece” la intervención del autor, se han alternado con las tendencias literarias con un estilo intervencionista en el que el lenguaje aparece como una barrera, del mismo modo que la superficie plana (bidimensional) de la pintura constituye un muro invisible que impide la interacción física con lo representado. Esos extremos literarios vendrían a estar ejemplificados por la obra narrativa de Dickens o Galdós en un caso, y Proust o Joyce en el otro (De Pablos, 2004).

La estética de la novela decimonónica se inclinó por el realismo; haciendo invisible al narrador y "transportó al lector a un cuerpo virtual situado en el lugar de la acción, un lugar al que convirtió en testigo directo de los hechos, tanto mentales como físicos, que parecían estar contándose por sí mismos” (Ryan, 2004: 21). Las técnicas narrativas del siglo XIX profundizaron en las cualidades inmersivas de la novela. Con la llegada del siglo XX, aparecieron tendencias estéticas que, como en el caso de la pintura, generaron movimientos alternativos hacia el otro extremo (prioridad de la forma sobre el contenido).

Con poco más de un siglo de existencia, el cine, arrastrado por su doble condición de arte e industria, ha sufrido una vertiginosa evolución en todos los ordenes (narrativo, técnico, social, económico, estético o moral) de manera que hoy se encuentra de nuevo ante una coyuntura difícil, sometido a la influencia abusiva de la imagen electrónica, es decir, la televisión y los soportes digitales. La saturación audiovisual ha llegado a embotar la capacidad de los espectadores para captar la representación audiovisual. Una posible vía que permita encontrar nuevos caminos puede ser una aproximación pedagógica que permita acudir a la historia vivida por este medio audiovisual.

El cine, o más precisamente su lenguaje, como arte del tiempo y el espacio, consideró desde sus orígenes a la representación pictórica como un referente importante. Así, la manera de encuadrar un plano fílmico sigue las mismas reglas que la pintura al tratarse en ambos casos de una 
representación bidimensional. Luis Lumière fue llamado el último pintor impresionista. En aquel entonces, finales del siglo XIX, la pintura en el cine aparecía como una referencia estética, y sirvan como ejemplo las películas bíblicas que se hicieron durante los primeros años de existencia del cinematógrafo. Las relaciones entre el cine y la pintura, planteadas a otros niveles, no apoyadas en la imitación de las formas pictóricas, irrumpen a partir de los años treinta del siglo XX, cuando el cine comienza a liberarse de las formas elementales de narración, tales como el sistema de géneros (que ya entró en crisis a partir de la segunda guerra mundial), o de la puesta en escena teatral.

\section{La pintura en el cine y el cine en la pintura}

Los posibles elementos de la influencia del cine sobre diferentes manifestaciones plásticas, y en concreto sobre la pintura, son rastreables a partir del análisis comparado entre pintores y cineastas. Temas, tratamientos, estilos encuadres o maneras de iluminar han influido en distintos creadores a lo largo del siglo XX (Ortiz y Piqueras (1995). Sin embargo, es una influencia que debe considerarse mutua, es decir, que se ha producido en las dos direcciones (Shaefer y Salvato, 1990). Este doble paralelismo es más evidente en pintores realistas preocupados por temáticas que el cine ha abordado específicamente. El gran director de fotografía hispanocubano Néstor Almendros ha mencionado en sus memorias tituladas Días de una cámara (1990) la utilidad que tiene para su trabajo estudiar el manejo de la luz en pintores como Vermeer, La Tour, Rembrandt, Caravaggio, Manet o Gaugin.

En cuanto a la influencia del cine en la pintura también existen evidencias significativas. José Luis Borau además de haber dado grandes películas al cine español como Furtivos (1975), ha desarrollado una interesante aportación teórica y didáctica en relación con el cine. Este cineasta aragonés ha analizado la influencia del cine en la pintura del siglo $\mathrm{XX}^{1}$, a la que ayudó en "su afán de reflejar el movimiento" y en "la búsqueda de nuevos encuadres". Para Borau son tres las características del cine "trasvasadas" a la pintura: "el manejo artificial de la luz, el encuadre y la posibilidad de reflejar el movimiento". Este cineasta y académico señala que desde que el cine dispuso de una gramática visual propia y renunció a expresarse únicamente en planos fijos y generales, "aprendió a descomponer la acción en imágenes parciales". "La cámara fragmenta la supuesta realidad, la disecciona". Lo que le lleva a afirmar que "el cine ha contribuido a reencuadrar la pintura moderna". Uno de los artistas que mejor ha reflejado el peso del cine en la pintura ha sido, según Borau, Francis Bacon, admirador de Eisenstein y Buñuel, que ha utilizado en el lienzo el plano-contraplano típico del cine y ha intentado reflejar el movimiento. Aunque, el máximo 
exponente del afán de la pintura por captar el movimiento, que sí se da en el cine, fue el movimiento futurista representado por las obras de artistas como Marinetti y Boccioni.

Borau (2003) afirma que «el cine lleva un siglo estimulando el conocimiento, la imaginación y hasta el espíritu artístico de gran número de creadores, pese a que algunos de ellos lo hayan negado, quizá por no ser siquiera conscientes del hecho». Y esa influencia puede calibrarse «por la frecuencia e intensidad con que [la pintura] adopta formas o maneras características de la pantalla, no por la presencia de objetos y personajes propios de la misma o de lo que podríamos llamar a su parafernalia». "Nadie puede negar que el séptimo arte ha contribuido a reencuadrar la pintura moderna". Para el cineasta aragonés, el cine "aparte de enriquecer con perspectivas y proporciones inéditas, así como con nuevos criterios luminosos, ha aproximado un poco más la pintura al movimiento, su eterna aspiración".

Respecto al uso artificial de la luz, Borau explica que "buena parte de los artistas barrocos o románticos manipularon la luz", y construyeron "auténticas escenografías luminosas" como Rembrant, Turner o Caravaggio. También encontramos esta situación en los artistas contemporáneos como Hockney "quintaesencia del tecnicolor". En cuanto al desenfoque de las pinturas, Borau explica que si bien pueden confundirse con "incertidumbres post-impresionistas", ello "no descarta una influencia cinematográfica simultánea".

La influencia del cine también se ha hecho patente en otras manifestaciones plásticas del siglo XX como el cómic o las historietas dibujadas. Esta relación ha sido estudiada por autores como Román Gubern, Luis Gasca o Javier Coma. Un ejemplo muy evidente es el del dibujante norteamericano Will Eisner en cuya serie The Spirit, realizada a partir de los años cuarenta, la planificación y la manera de encuadrar las viñetas es inequívocamente cinematográfica.

\section{La poesía visual de Víctor Erice}

Nacido en Carranza (País Vasco) en 1940, Víctor Erice se licenció en Derecho y Ciencias Políticas y Económicas. En los primeros años sesenta ingresó en la Escuela Oficial de Cine de Madrid para cursar la especialidad de dirección. De esta época son sus primeros cortometrajes: En la Terraza (1961), Páginas de un Diario (1962), Los días Perdidos (1963). Se trata de un período de formación dentro del cual también podemos citar sus trabajos como guionista en el film de Antonio Eceiza El próximo Otoño (1963) y en Oscuros sueños de Agosto (1967) dirigida por Miguel Picazo. En esa 
época Erice dirigió también otro cortometraje titulado Entre Vías (1966). De forma paralela escribió crítica de cine en diversas publicaciones, entre ellas Nuestro Cine.

En el año 1969 debutó en el largometraje dirigiendo uno de los episodios de Los Desafíos, junto con José Luis Egea y el malogrado Claudio Guerín. Se trata de tres visiones distintas sobre las manifestaciones de la violencia. En 1973 rueda la premiadísima El espíritu de la colmena. Diez años después El Sur y en 1992 El sol del membrillo, un documental sobre el pintor Antonio López, donde precisamente analiza el proceso de creación artística de una obra pictórica, reflejándolo desde un punto de vista cinematográfico. En su película El sol del membrillo (1992) Víctor Erice precisamente propone una aproximación a las relaciones entre pintura y cine, al mostrar el proceso de creación de un cuadro por parte del pintor Antonio López. Este film documental nos habla de la pintura en el cine y del paso del tiempo. Durante siglos los pintores han tratado de dotar de movimiento a la pintura. La incorporación del tiempo ha sido uno de los logros fundamentales de los pintores modernos. En el caso de la película citada, se apoya la tesis de que pintar la luz equivale a pintar el tiempo, al menos esa es la intención de los dos artistas (Antonio López y Víctor Erice).

Todas las películas de Víctor Erice presentan microcosmos en los que las relaciones personales se entrelazan de manera que las historias trascienden la realidad concreta y se elevan en forma de metáforas muy poderosas sobre la condición humana. El espíritu de la colmena atraviesa la dura posguerra española tomando la anécdota de la llegada del cinematógrafo a un perdido pueblo castellano. El punto de vista de dos niñas muy pequeñas fascinadas por una película de terror, mezclando fantasía y realidad, creyendo ver pistas del monstruo cinematográfico en su pueblo, donde el padre trata de iniciarlas a la vida, y en un marco donde el miedo y la represión están latentes, marca los hitos de una narración intensamente poética. Sus imágenes plenas de matices parecen utilizar las luces y claroscuros que vemos en cuadros de Rembrandt, Velázquez, Vermeer o Goya, consiguiendo transmitir una atmósfera creada por las relaciones humanas.

Su último film, Alumbramiento, rodado en blanco y negro y estrenado en el año 2002, nos presenta los primeros diez minutos de vida de un ser que va a quedar marcado por el momento y las circunstancias en las que nace: el 28 de junio de 1940 en el País Vasco, durante la II Guerra Mundial. Después del parto, fundida con los sonidos del campo, una nana trata de consolar el llanto del recién nacido. Alumbramiento, tiene únicamente una duración de diez minutos, ya que forma parte del proyecto titulado Ten Minutes Older. Un film colectivo producido por Nicholas McClintock y en el que intervienen otros doce cineastas (Jim Jarmusch, Aki Kaurismaki, Jean-Luc 
Godard, Bernardo Bertolucci, Wim Wenders o Wong Kar-Wai, entre otros), cada uno de los cuales ha rodado un episodio de diez minutos.

Víctor Erice ${ }^{1}$ confiesa haber descubierto la realidad de las relaciones entre la pintura y el cine con Robert Bresson, un artista con experiencia previa como pintor y gran amante del teatro. Bresson se convierte en cineasta para superar a la pintura en cierto modo. No hay una película suya en la que se pueda ver la imaginería de un plano, no habla de actores sino de modelos, no existen imágenes bellas sino imágenes necesarias. Aquí surge la modernidad, en este medio de expresión.

Erice, señala la idea de que la evolución contínua es necesaria para la supervivencia de las artes, afirmando que John Ford es un clásico de la historia del cine clausurado. Fundador de la narración cinematográfica clásica, lo que tipifica el cine de Ford es que vivió en un presente (cinematográfico) sin historia, frente a los cineastas actuales que viven bajo una influencia que impide tener un presente; donde la única vía trascendente es la de una educación artística, hoy muy lejos de una puesta en práctica coherente por parte de nuestro sistema educativo. ${ }^{2}$

Rafael Cerrato (2006) analiza en su monografía sobre la obra de Víctor Erice las profundas relaciones que las películas del cineasta vasco mantienen con determinados pintores. A partir de una profunda reflexión sobre las formas de representación cinematográfica vigentes en sus años de formación - los sesenta y setenta del siglo XX--, Erice se plantea abordar un cine poético.

Antecedentes en ese recorrido los encuentra en cineastas como Bresson o Pasolini. El concepto central de esta propuesta gira en torno a la formulación de un lenguaje poético basado en el uso de la narración audiovisual, al que la pintura puede aportar las referencias necesarias para abordar muchas de las cuestiones estéticas y temáticas a resolver. El mismo cineasta señala que "la pintura va a ayudar al cine a liberarse de los artificios literarios y teatrales heredados desde su nacimiento, salvándolo de las fórmulas narrativas y las convenciones dramáticas presentes en los guiones que la industria le ha impuesto tradicionalmente” (Erice, 1998, 120).

Cerrato propone la fórmula del lenguaje pictórico-poético, de manera que identificándolo conceptualmente, lo aplica al análisis de la obra de Víctor Erice. Este lenguaje, altera la lógica con la que los seres humanos percibimos la naturaleza, al transmitir un contenido cargado de significados interpretables. Lo que Cerrato formula como un “contenido psíquico”. Ese contenido “añadido” que aportan las grandes obras de pintores realistas como Velázquez, Rembrandt, Rubens, Caravaggio, Vermeer, Goya y en el siglo XX artistas como Balthus, Edward Hopper y Antonio López, es lo que pretende traducir Erice al lenguaje cinematográfico. 


\section{Edward Hopper, un pintor cinematográfico}

Hopper nació en Nyack, Nueva York, en 1882, un año después que Picasso, pero su obra artística no tiene nada que ver con el revolucionario pintor andaluz. Los excelentes trabajos publicados por la biógrafa Gail Levin $(1995,1998)$ nos permiten conocer de manera pormenorizada el transcurso vital del pintor y nos muestran, de manera fehaciente su relación con el cine, que sus hagiógrafos recuerdan permanentemente. En sus años de aprendizaje, Hopper se relacionó con Robert Henri, que fue uno de sus profesores, y con la Ash-can School, un grupo artístico que reflejó la vida de los barrios pobres en las pujantes ciudades de los Estados Unidos, aunque lejos de cualquier intención social o reivindicativa. Hopper se trasladó a la ciudad de Nueva York a principios del siglo XX, y allí viviría, con pequeñas interrupciones, hasta su muerte, más de sesenta años después.

En su juventud, viajó a París, capital artística del mundo en esos años. De hecho, Hopper viajó a Europa en varias ocasiones, durante su etapa de formación, y vivió en la capital francesa, donde conoció el tratamiento de la luz que hacían los pintores impresionistas, aunque la rápida sucesión de las vanguardias artísticas europeas no le supuso una influencia determinante. No obstante, profundizó en algunas tradiciones europeas como los paisajistas románticos ingleses, Turner y Constable, y sin duda fue sensible a otras influencias, como Rembrandt, Degas o Manet. De la pintura impresionista aprendió la trascendencia vital de la luz. Hopper siempre se mantuvo dentro de la pintura figurativa. Toda su obra, hasta su muerte acaecida en 1967, se desarrolló sin apenas variaciones, ajeno a las novedades creativas tanto europeas como americanas. De hecho, fue uno de los fundadores de la revista Reality, que se oponía frontalmente al arte abstracto de Mark Rothko o Jackson Pollock . Su esposa, Jo Nivison Hopper, también pintora, de personalidad muy distinta, le acompañó durante toda su vida y resultó ser un apoyo fundamental.

A Edward Hopper se le conoce como el pintor del espacio, de la luz y de la soledad. Su pintura muestra un paisaje típicamente estadounidense formado por motivos urbanos, gasolineras, moteles, bares, trenes..., en los que puede intuirse la melancolía, la soledad que caracteriza, según Hopper, al individuo urbano, tan presente en la cultura norteamericana del siglo XX. Su mirada de la América del siglo XX representa una visión poco complaciente, opuesta a la reflejada por pintores contemporáneos como Norman Rockwell; un pintor costumbrista que ha reflejado la cara amable de Norteamérica, frente a Hopper que "ha visto" el lado oscuro, el drama individual y cotidiano. Esta visión de la América contemporánea reflejada en una cotidianidad urbana o rural donde los personajes representados hacen participes al espectador de sus estados de ánimo, ha sido reflejada pictóricamente a través de lo que los especialistas en su obra denominan una “mirada 
cinematográfica”. Aunque es evidente que la influencia de su pintura sobre el cine también es una realidad. La representación visual de la cotidianidad está presente en la obra de cineastas como Robert Altman, en cuya filmografía la influencia estética de Hopper parece hacerse visible. Un ejemplo específico puede ser el film Vidas cruzadas (1993), basado en varios relatos de Raimond Carver, donde dicha cotidianidad es el punto de partida para relatar cómo la vida de unas personas corrientes se entrecruza, compartiendo ilusiones y tragedias.

La pintura de Hopper es narrativa, es decir, nos propone un instante que forma parte de una realidad que fluye de manera contínua, en la que el tiempo tiene un papel fundamental. Los personajes retratados están afectados por sucesos ocurridos con anterioridad y que además no pueden evitar la presencia y continuidad de lo que les rodea.

Edward Hopper fue un gran aficionado al cine, de tal manera que el séptimo arte resultó ser para el pintor norteamericano fuente de inspiración. Reconoció su admiración por films como Los niños del paraíso de Marcel Carné (1945), Forajidos, de Robert Siodmak (1946), El Halcón maltés de John Huston (1941) o Marty (1955) de Delbert Mann. Estas películas le inspiraron directamente algunos de sus trabajos más significativos.

La importancia de Hopper no radica en su rompimiento con las normas estéticas o la búsqueda de nuevas técnicas pictóricas, sino en que puso de manifiesto que las imágenes que creamos parten inequívocamente de la realidad de las cosas que nos rodean y, sin embargo, son expresión de un mundo personal e íntimo, por eso su aportación es tan importante para los creadores de imágenes. Si indagamos en films concretos, podemos encontrar “lienzos de Hopper” reconstruidos cinematográficamente en ellos. A modo ilustrativo para los lectores pueden citarse: El Eclipse de Michelangelo Antonioni (1962); Llueve sobre mi corazón de Francis Ford Coppola (1969); La última película de Peter Bogdanovich (1971); Dinero caído del cielo de Herbert Ross (1981); Bagdad Café de Percy Adlon (1987) y de forma especial, las películas de Todd Haynes, Safe (1995) y Lejos del cielo (2002).

Los paisajes urbanos pintados por Hopper transmiten desasosiego. Los objetos inanimados parece cobrar vida. Los temas abordados por Hopper son nítidamente americanos, es la plasmación de la realidad americana de la época. Sus temas y personajes son representados con una sensación de atemporalidad, o de tiempo detenido. Como de nuevo advierte José Luis Borau ${ }^{4}$, en referencia a Hopper, la representación de la realidad viene caracterizada en el pintor norteamericano, porque queda representada en sus elementos esenciales, característicos, prescindiendo de todo lo superfluo. 
Esa capacidad para representar lo esencial, traspasando el localismo o la realidad concreta, convierte las pinturas de Hopper en mensajes universales.

En este sentido, la búsqueda de lo esencial es un camino que culmina en la pintura abstracta donde la realidad ha quedado reducida a una idea o concepto. Es un camino que comenzó con Velázquez muchos años antes. Hopper partiendo de una realidad, crea una abstracción de esa realidad, fundamentalmente a través de la luz, la forma y el color. La luz representada por Hopper es una luz realista, descarnada, tan poco poética como exige el mundo cotidiano, en realidad es la luz de la vida, alejada de las ensoñaciones. Hopper representa la alienación consustancial de la vida moderna, la convivencia impersonal en las grandes urbes, la soledad vivenciada mientras estas rodeado de gente. Submundos de violencia psicológica y sufrimiento bajo la apariencia de una cotidianeidad perfectamente normal, pero que convive con la superstición y el miedo, porque la diferencia entre el bien y el mal, en lo cotidiano, no resulta fácil de discernir.

Como señala Higinio Polo (2005) es fácil reconocer la relación de Hopper con el cine. Su deuda con las películas del cine negro de la gran época de Hollywood, anterior a la caza de brujas promovida por el senador McCarthy, resulta visible en muchas de sus pinturas. El cine funciona con metáforas, transforma una historia anecdótica en un mensaje universal, entendible por muchos. En ese sentido la pintura "narrativa” de Hopper, que partiendo de hechos cotidianos trasciende la mera anécdota, ha pesado en muchos cineastas. La influencia de Edward Hopper en algunos directores de cine, además de relevante, se ha mantenido a lo largo del tiempo. Desde Alfred Hitchcock hasta David Lynch es posible identificar conceptos visuales, soluciones referidas a la iluminación y el encuadre o “atmósferas psicológicas” que de manera inequívoca han sido sugeridas por este pintor. Esas influencias son claramente identificables en películas como La sombra de una duda (1943), La ventana indiscreta (1954), Vértigo (1958) o Psicosis (1960) de Alfred Hitchcock; La noche del cazador (1955) de Charles Laughton; Matar a un ruiseñor (1962) y Verano del 42 (1971) de Robert Mulligan; Malas tierras (1973) y Días del cielo (1978) de Terrence Malick; A quemarropa (1967) de John Boorman; Alicia ya no vive aquí (1974) de Martin Scorsese o Dinero caído del cielo (1981) de Herbert Ross. También directores no norteamericanos han sido influidos de manera muy visible por Hooper; en este sentido debe destacarse especialmente al cineasta alemán Win Wenders, con películas como El amigo americano (1977), París, Texas (1984) y El final de la violencia (1997).

Christopher Frayling, en su excelente estudio dedicado a la obra de Sergio Leone (2002), al hacer referencia a la magistral película Érase una vez en América (1984), explica que algunas de las pinturas de Nueva York realizadas por Edgard Hopper, concretamente “Drug Store” (Tienda) (1927) 
y “Nighthawaks” (Halcones de la noche) (1942) proporcionaron la inspiración visual para algunas localizaciones del film. Hopper, que pasó la mayor parte de su vida en Nueva York, buscó representar la "soledad de la gran ciudad”. Muchos de sus cuadros dedicados a la representación urbana parecen instantáneas sacadas de un "film noir”. El mismo Sergio Leone ha declarado, en relación a las pinturas de Hopper que “funcionaban en mi imaginación”.

La influencia de Hooper en el cine se ha mantenido hasta nuestros días y además sobre directores muy significativos, como es el caso de David Lynch, en films como Terciopelo azul (1986) Una historia verdadera (1999) y Mulholland Drive (2001), o Sam Mendes en Camino a la perdición (2002). El cineasta alemán Win Wenders, a propósito de su último film hasta la fecha, Don’t come knocking (2005) ha declarado en relación a la influencia del pintor: "Esa imagen hopperiana es buscada conscientemente. Amo de ese pintor la ausencia de detalles; ese ir a lo mínimo indispensable. Hay sitios de los Estados Unidos donde pones la cámara y te sale un cuadro de Hopper." 5

En sus conceptos y temáticas, las telas de Hopper, aunque le precedan, recuerdan los relatos cortos de Raymond Carver, al viajante de Arthur Miller, a los personajes condenados de John Steinbeck, o las historias de Truman Capote. Sus cuadros parecen ahogar un grito, ocultar un desasosiego vital que, sin embargo, se revela al espectador atento de su obra. La idea de soledad, la desesperada sensación de que todo se ha perdido, está en esos personajes: es el reverso del sueño americano. Hopper fue consciente de que la vida americana había cambiado después de la segunda guerra mundial. Esa sensación de pérdida de un modo de vida, queda reflejada en sus pinturas. En la obra titulada "Habitación de hotel” (1931) quedan representadas de forma fehaciente algunas de las temáticas más características del pintor: la soledad, la actitud melancólica, el viaje o la necesidad de ensimismamiento. 


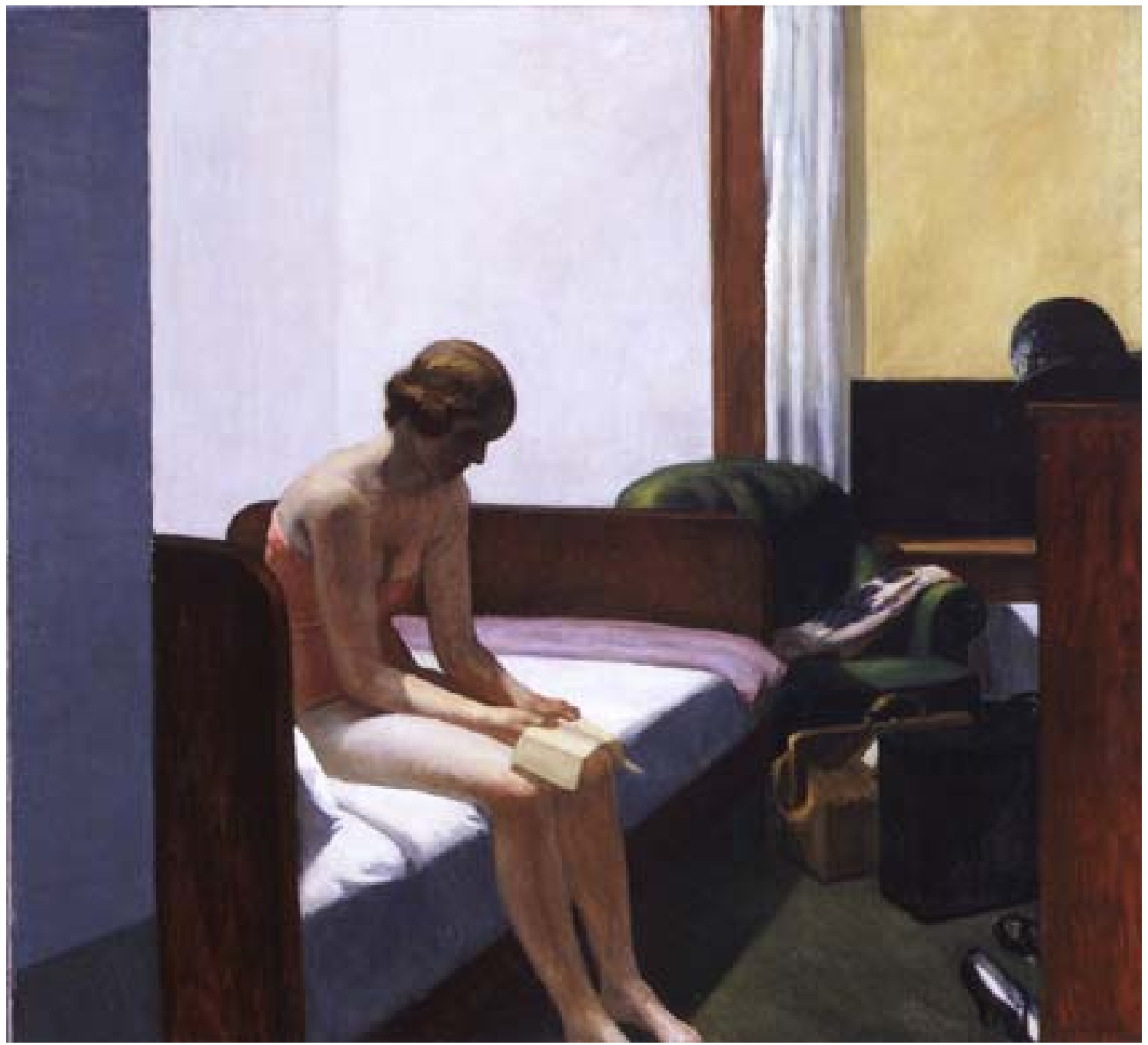

Habitación de hotel (1931). Museo Thissen-Bornemisza. Madrid.

Hopper en sus escenas urbanas, ha recogido con mucha mayor frecuencia a personajes femeninos, con más posibilidades para representar los estados de ánimo. Su obra carece de sentido del humor. Aleja así su pintura de la producción del arte pop posterior. A través de su obra quería pintarse a sí mismo, pero nos enseñó, sin pretenderlo, las consecuencias del capitalismo, la realidad del sueño americano encerrado en un frío restaurante o en una sórdida habitación de hotel. Sus espacios son retratos psicológicos de cierta manera americana de concebir la existencia. Sus personajes ensimismados y melancólicos, sus calles desoladas y silenciosas y sus cafeterías y cines siempre habitados por seres solitarios parecen reflejar las vicisitudes del hombre moderno. 


\section{Epílogo}

Desde un punto de vista formativo y en base a una lógica visión interdisciplinar, cada vez más necesaria, el cine merece un mejor tratamiento curricular en el marco del sistema educativo español. Conviene aprovechar su potencialidad formativa y su capacidad simbólica para interpretar mejor otras manifestaciones artísticas, tal como hemos tratado de reflejar en este artículo. El cine, al igual que las artes mayores como la pintura, se vincula a la educación como reflejo y análisis de la sociedad. Forma parte del lenguaje contemporáneo y las formas expresivas que nos rodean; y sin duda es un poderoso factor en la proyección de valores y contravalores sociales y culturales.

Es necesario sensibilizar, motivar y responsabilizar al profesorado sobre la importancia en el campo educativo de medios como el cine, que en sus diferentes soportes admite muchas posibilidades formativas, especialmente desde la perspectiva del trabajo interdisciplinar. La visión del arte como un conjunto de manifestaciones, que en muchos casos mantienen profundas relaciones entre sí, sin duda supone una aproximación más integral a la realidad cultural desde un punto de vista educativo. En definitiva, se trata de establecer maneras de abordar y analizar las vías de conocimiento organizado, de manera que no sólo contemplen la reproducción del escenario cultural del que formamos parte, sino también su reconstrucción reflexiva y crítica en toda su complejidad.

Roberto Rossellini, fundador del neorrealismo italiano, ha sido un cineasta especialmente sensibilizado por el papel formativo de los medios audiovisuales. Ese valor es formulado por el propio director italiano en los siguientes términos: "El material filmado puede convertir la escuelaauditorio en escuela-laboratorio (...). Una educación de los contactos sociales presupone un conocimiento de las relaciones humanas” (2001: 148).

\section{BIBLIOGRAFÍA}

ALMENDROS, N. (1990): Días de una cámara. Barcelona, Seix Barral.

BORAU, J.L. (2003): La pintura en el cine. El cine en la pintura, Madrid, Ocho y medio.

CERRATO, R. (2006): Víctor Erice. El poeta pictórico. Madrid, Ediciones JC.

DE PABLOS, J. (2004): De Velázquez al hipertexto: algunas implicaciones socioculturales. Aula

Abierta, Universidad de Oviedo, $\mathrm{n}^{\circ} .84$, pp. 103 a 116.

FRAYLING, CH. (2002) Sergio Leone. Algo que ver con la muerte. Madrid, T\&B. 
KRANZFELDER, I. (1998): Hopper. Colonia, Taschen.

LEVIN, G. (1995): Edward Hopper: An Intimate Biography. Nueva York, Knopff.

LEVIN, G. (1998): Hopper's Places (segunda edición). University of California Press.

MARKER, S. (1990): Edward Hopper. Leicester, Magna Books.

ORTIZ, A Y PIQUERAS, M.J. (1995): La pintura en el cine. Cuestiones de representación visual. Barcelona, Paidós.

POLO, H. (2005): Edward Hopper: desolada América. El viejo topo, nº. 209-210, julio-agosto.

RENNER, R.G. (1991): Edward Hopper. Colonia, Taschen.

ROSSELLINI, R. (2001): Un espíritu libre no debe aprender como un esclavo. Escritos sobre cine y educación. Barcelona, Paidós.

RYAN, M. L. (2004): La narración como realidad virtual. Barcelona, Paidós.

SCHAEFER, D. Y SALVATO, L. (1990): Maestros de la luz. Conversaciones con directores de fotografía. Madrid, Plot.

VV.AA. (1998): Víctor Erice, Banda Aparte. Revista de cine-formas de ver, nº 9 y 10.

\section{NOTAS}

${ }^{1}$ Discurso de ingreso en la Real Academia de Bellas Artes de San Fernando titulado "El cine en la pintura". (Leído el 21 de abril de 2002)

${ }^{2}$ Apuntes de E. Barriendos tomados durante el encuentro-diálogo entre Víctor Erice y José Luis Guerín en la clausura del seminario "La pintura en el cine: una aproximación", celebrada en Valencia, el once de noviembre de 2005. (Consulta en la web: http://www.zinema.com/textos/lapintur.htm)

${ }^{3}$ Ibidem.

${ }^{4}$ Entrevista incluida en el documental Edward Hopper. El pintor del silencio (Canal +, 2005)

${ }^{5}$ Entrevista publicada en El País, 19/08/2005. 